\title{
LATAR CERPEN "MADRE" DALAM KUMPULAN CERITA MADRE KARYA DEWI LESTARY (ANALISIS STRUKTURAL)
}

\author{
Berty Sapiya \\ Universitas Pattimura \\ e-mail: bertysapya6@gmail.com
}

\begin{abstract}
Abstrak: Penelitian ini menggunakan kajian struktural untuk mengkaji unsur latar dalam karya prosa. Metode yang digunakan, yaitu metode deskriptif yang bertujuan untuk mendeskripsikan latar cerpen Madre dalam kumpulan cerita Madre karya Dewi Lestari.Teknik Pengumpulan data yakni, teknik baca, catat, pustaka.Analisis data berfokus pada unsurunsur latar, yaitu, latar tempat, waktu, suasana, sosial budaya.Hasil penelitian ini menunjukan bahwa latar dalam cerpen Madre karya Dewi Lestary terdapat 4 jenis latar yaitu latar tempat, waktu, suasana, sosial budaya. Dari keempat jenis latar yang paling dominan pada cerpen ini adalah latar tempat dikarenakan dari awal cerita sampai akhir cerita hampir semua jalan ceritanya di dalam Toko roti Tan de Bakker di kota Jakarta.
\end{abstract}

Kata kunci: Latar Cerpen, Analisis Struktural. 
SETTINGOF "MADRE" SHORT STORY IN DEWI LESTARY'S

MADRE

(STRUCTURAL ANALYSIS)

\author{
Berty Sapiya \\ Pattimura University \\ e- mail: bertysapya6@gmail.com
}

\begin{abstract}
Abstrak: This study uses a structural study in the form of qualitative. The method uses is the descriptive method which aims to describe the setting of Madre story in the collection of Madre stories by Dewi Lestari. Data collection techniques are, reading, techniques, note taking techniques and references techiques. Data analisis focuses on setting elements namely, place setting, time, atmostphere and social culture. The result of this study show that setting in short story Madre by Dewi Lestari there are 4 setting types is place setting, time, atsmosphere and social culture. From the fourth setting types above the most dominant in this short story is the place setting because it' $\mathrm{s}$ from beginning until the last story there almost the all storyline there in the Tan de Bakker Bakery at Jakarta City.
\end{abstract}

Key Word: Setting Short Story, Structural Analysis 


\section{A. PENDAHULUAN}

Latar merupakan salah satu unsur intrinsik yang membangun sebuah karya sastra. Latar juga membuat sebuah cerita dalam karya sastra menjadi lebih hidup, sehingga pembaca dapat merasakan suasana, kejadian, dan peristiwa pada cerita. Latar juga memberikan pijakan cerita secara konkret dan jelas. Hal ini penting untuk memberikan kesan realistis kepada pembaca, menciptakan suasana tertentu yang seolah-olah sungguh ada dan terjadi.

Sebuah karya sastra memiliki bermacam-macam latar dalam ceritanya, yaitu latar tempat, waktu, sosial budaya dan suasana. Keempat latar tersebut saling berkoherensi dalam membangun sebuah karya sastra menjadi lebih hidup. Dengan demikian, pembaca dapat merasakan atau seakan-akan berada pada situasi dalam cerita tersebut. Sebuah karya sastra tidak bisa hidup tanpa latar dikarenakan latar merupakan salah satu unsur yang menghidupkan sebuah cerita. Hal ini yang terjadi pada cerpen Madre karya Dewi Lestari. Latar yang paling mendominasi dalam cerpen tersebut adalah latar tempat yaitu toko roti Tan de Bakker di kota Jakarta. Namun, dengan latar ini pengarang mampu membuat cerpen Madre ini begitu hidup sehingga menarik untuk dibaca. Cerpen ini juga tidak monoton sehingga membuat pembacanya terkesan. Jadi pembaca tidak merasa bosan dengan cerita ini.

Secara garis besar cerpen Madre karya Dewi Lestari menceritakan tentang kehidupan sehari-sehari tokoh yang ada dalam cerpen. Selain latar tempat, ada juga latar sosial budaya yang begitu kental digambarkan untuk menjelaskan kehidupan etnis Tionghoa yang hampir sebagian besar menghabiskan waktunya menjadi seorang pengusaha dan itu terjadi secara turun-temurun dari kakeknya sampai kepada cucunya. Dalam Cerpen Madre juga terdapat latar suasana yang bertema perjuangan. Hal ini yang membuat latar tersebut terkesan menarik, dikarenakan latar suasananya tidak sama dengan cerpen-cerpen lainnya. Pada cerpen Madre suasananya lebih terbangun dari tokoh pembantunya, Pak Hadi dan Mey yang lebih bersemangat untuk memajukan dan memperjuangkan Madre tetap hidup, sedangkan tokoh utamanya Tansen hanya menjadi penonton. Sedangkan pada cerpen-cerpen lainnya biasanya tokoh utamanya yang paling berperan penting dalam sebuah cerpen.

Cerpen termasuk dalam salah satu jenis genre sastra imajinatif, yaitu prosa. Cerita yang terdapat dalam cerpen adalah cerita yang dibaca sekali duduk. Selain itu cerpen harus menimbulkan perasaan pada pembaca bahwa jalan ceritanya pertamatama menarik perasaan, kemudian menarik pikiran. Hal ini yang terjadi pada cerpen Madre, dikarenakan ceritanya menarik perasaan yang kemudian menarik pikiran pembaca 
Cerpen Madre adalah salah satu cerpen yang ditulis oleh Dewi Lestari atau sering dikenal dengan panggilan Dee. Dewi Lestari adalah seorang pengarang yang juga berprofesi sebagai penyanyi. Banyak karyanya yang telah difilemkan yang membuat namanya melejit menjadi penulis papan atas. Karya-karyanya yang telah difilemkan antara lain, Perahu kertas1(200), Perahu kertas2(2012),Rectoverso(2003) dan lain-lain.

Alasan pemilihan Cerpen Madre sebagai penelitian ini, dikarenakan dalam cerpen Madre ditemukan latar yang berbeda dari karya sastra pada umumnya, yakni latar tempat dalam cerpen Madre ini hampir sebagian besar latar tempatnya terjadi pada toko roti tan de bakker. Selain itu, latar waktunya hanya memperlihatkan perjalanan usia dari sebuah adonan. Hal ini yang membuat latar waktu menjadi menarik, yang menjadi pembeda dengan cerita pendek lainnya. Latar suasana pada cerpen Madre terbangun oleh tokoh pendamping, sementara tokoh utamanya kurang terlalu berpartisipasi dalam membangun latar suasana. Latar sosial budayanya menjelaskan tentang kehidupan orang etnis tionghoa, yakni hampir semua orang etnis tionghoa, dari remaja sudah menghabiskan waktu di tempat-tempat bisnis. Hal ini yang membuat latar dalam cerpen Madre sangat menarik untuk diteliti. Peneliti memilih.

Peneliian ini menggunakan kajian strukuralisme. Kajian strukturalisme adalah kajian yang membahas mengenai unsur intrinsik atau unsur yang membangun karya sastra dari dalam, salah satunya adalah unsur latar yang akan dianalisis penulis dalam cerpen Madre karya Dewi Lestari atau sering di kenal dengan panggilan Dee. Dengan menggunakan kajian strukturalisme dapat mempermudah peneliti dalam menganalisis latar pada cerita. Hal tersebut juga sangat berguna dalam mata pelajaran sastra (prosa) terutama tentang cerpen dalam pembelajaran bahasa Indonesia di sekolah-sekolah. Dengan demikian hasil analisis penelitian ini dapat digunakan sebagai contoh dalam mata pelajaran bahasa Indonesia khususnya pada materi cerpen. Oleh karena, itu maka perlu dilakukannya analisis latar dalam cerpen Madre dalam kumpulan cerita Madre karya Dewi Lestari dengan menggunakan kajian strukturalisme.

\section{B. METODE PENELITIAN}

Penelitian ini menggunakan metode penelitian deskriptif kualitatif. Data penelitian ini adalah kata-kata, kalimat, dan frasa yang terdapat dalam cerpen Madre. Sumber data penelitian ini adalah naskah cerpen Madre, Salah satu dari ketiga belas cerpen yang terdapat di dalamnya. Teknik Pengumpulan data yang digunakan adalah teknik penelusuran pustaka, baca, dan teknik catat. 
Teknik analisis data yang digunakan dalam penelitian ini adalah teknik deskriptif kualitatif. Prosedur analisis Cerpen Madre adalah sebagai berikut.

1. Membaca secara seksama isi cerpen Madre pada karya Dewi Lestari yang telah diambil sebagai objek penelitian secara seksama dan berulang-ulang.

2. Membaca/mengklarifikasikan persoalan-persoalan yang berkaitan dengan masalah penelitian yaitu analisis latar cerpen Madre dalam kumpulan cerita Madre karya Dewi Lestari.

3. Mencatat semua hasil klasifikasi data ke dalam kartu warna-warni yang bertujuan sebagai penunjang dari proses pencarian dan penganalisian data tentang latar pada cerpen Madre.

4. Menganalisis data dengan menggunakan kajian strukturalisme dan latar berdasarkan data yang telah dianalisis tentang latar pada cerpen Madre karya Dewi Lestari.

5. Membuat kesimpulan dengan menggunakan kajian strukturalisme dan latar berdasarkan data yang telah dianalisis tentang latar pada cerpen Madre karya Dewi Lestari.

Data yang diperoleh pada saat penelitian perlu dicek keabsahannya. Teknik yang digunakan untuk mengecek dan memeriksa hasil penelitian adalah triangulasi. Triangulasi adalah teknik pemeriksaan keabsaan data yang memanfaatkan sesuatu yang lain. Ada empat triangulasi menurut Denzim (dalam Moleong, 2012:330) sebagai teknik pemeriksaan yang memanfaatkan sumber, metode, penyelidik, dan teori. Triangulasi yang digunakan adalah triangulasi teori untuk mengecek keabsahan data yang dikumpulkan untuk dianalisis dan saya bandingkan atau pduka dengan teori yang relevan.

\section{PEMBAHASAN}

Data dan hasil analisis yang dilakukan oleh penulis terhadap cerpen Madre karya Dewi Lestari dalam Buku Kumpulan Ceria Pendek Madre dengan menggunakan kajian Strukturalisme. Data yang disajikan berupa usur-unsur latar pada Cerpen Madre. Unsur-unsur latar yang dimaksud yaitu latar menguraikan tempat, latar waktu, latar suasana, dan latar sosial-budaya. Berikut ini penulis akan data beserta analisis terhadap cerpen tersebut. 


\section{Latar Tempat}

Latar tempat dalam Cerpen Madre mendeskripsikan tempat suatu peristiwa cerita terjadi dan kaitannya dalam memperjelas jalan cerita. Pengarang secara eksplisit menggambarkan latar tempat dengan menyebutkan nama lokasi dimana tempat tokoh atau si pelaku mengalami kejadian atau peristiwa dalam cerita. Unsur tempat yang dipergunakan berupa tempat-tempat dengan nama tertentu dan lokasi tertentu tanpa nama jelas. Tempat-tempat bernama adalah tempat yang dijumpai dalam dunia nyata. Seluruh cerita dalam cerpen Madre karya Dewi Lestari menggunakan setting atau tempat di kota Jakarta. Dikisahkan Tansen sebagai tokoh utama yang tinggal di Bali, pergi ke Jakarta untuk menghadiri pemakaman seorang kakek tua bersuku Tionghoa yang tidak lain adalah kakek dari ibunya sendiri. Kemudian, kejutan demi kejutan dia temui usai pemakaman kakek keturunan Tionghoa di Jakarta itu.

Sebagai turis domestik terdampar di ibu kota, itu tawaran yang paling kunanti. Tak ada yang lebih kuinginkan selain segera menyelesaikan urusan ini. Pulang ke Bali. Keluar dari kota pengap bernama Jakarta. (Madre, hal. 4)

Dini hari.tepat dua minggu sejak aku terdampar di Jakarta. Pak Hadi melemparkan celemek untuk kupakai. Menyusul penutup kepala.(Madre, hal 44.)

Pengarang dalam memaparkan Jakarta begitu banyak, namun ia lebih menekankan pada Toko Roti Tua di Jakarta yang menjadi asal terciptanya kisah Madre. Madre dalam cerita tidak hanya berperan sebagai latar atau pelengkap saja tetapi Madre adalah tokoh utama setelah Tansen karena Madre lah yang menjadi penyebab segala kejadian, peristiwa, hingga konflik dalam cerita tersebut.

\section{a. Tempat Pemakaman Umum Etnis Tionghoa}

Tempat Pemakaman Umum (TPU) Etnis Tionghoa merupakan tempat khusus bagi warga Etnis Tionghoa dikebumikan di akhir hayatnya, yang notabene kuburan tersebut berbeda dengan kuburan orang-orang bukan Etnis Tionghoa, kuburan Cina memiliki ciri khas dan gaya arsitektur tersendiri mulai dari bentuk kubur yang berukuran besar, batu nisan yang begitu besar, mausoleum (bangunan pelindung makam), yang berbenuk seperti atap rumah dan terbuat dari semen. Selain itu, di kuburan Cina terdapat tempat untuk menaruh persembahan bagi orang-orang yang datang berziarah dimakam tersebut. 
Latar tempat di TPU etnis Tionghoa ialah sebuah lokasi yang disebutkan secara langsung dalam cerpen. Diawal cerita Madre, tokoh utama "Tansen" menghadiri pemakaman seorang kakek tua bersuku Tionghoa yang berlokasi di Jakarta. dengan menyebutkan nama tempat dan kehadiran tokoh di tempat itu sudah pasti merupakan alur maju yang digunakan oleh pengarang untuk mengawali cerita.

Keganjilan ini pasti sebegitu mencoloknya. Di tengah TPU Etnis Tionghoa, muncul seorang pria berkulit gelap, rambut gimbal, kaus tanpa lengan, jins sobek-sobek. Sendirian. (Madre, hal. 2)

Sudah tidak ada siapa-siapa lagi di situ. Acara pemakaman selesai sejak setengah jam yang lalu. Sengaja aku datang terlambat agar tidak bertemu siapa-siapa. Misteri ini tak perlu bertambah ruwet dengan ekstra drama. (Madre, hal. 2)

Berdasarkan kutipan teks di atas, pengarang menceritakan awal mula kisah Madre dengan kehadiran tokoh utama "Tansen" menghadiri pemakaman seorang kakek tua bersuku Tionghoa.

Bukti bahwa lokasi TPU Etnis Tionghoa yang di datangi "Tansen" berada di Jakarta terdapat pada kutipan berikut.

Dia ikut membaca, "itu dekat kantor saya. Kalau mau ke sana, bisa ikut saya. Sekalian saya ke kantor." Sebagai turis domestik terdampar di ibu kota, itu tawaran yang paling ku nanti. Tak ada yang lebih kuinginkan selain segera menyelesaikan urusan ini. Pulang ke Bali. Keluar dari kota pengap bernama Jakarta. (Madre, hal5)

Keterangan dalam kutipan di atas merupakan cerita lanjutan dari keberadaan Tansen di tempat pemakaman. Saat itu ia bertemu dengan seorang pengacara dan percakapan mereka berakhir di sebuah kafe yang letaknya tidak jauh dari TPU etnis Tionghoa.Setelah itu Tansen diajak untuk bersama dengannya melakukan perjalanan ke alamat yang akan dituju oleh Tansen di Jakarta.

Hal yang dominan di latar tempat ini adalah kehadiran tokoh utama, pelaku utama dalam alur maju. Penulis seolah terlibat dalam ceritanya dan dia sendiri sebagai tokoh utama dalam cerita. Kisah inidimulai dengan munculnya tokoh utama yaitu Tansen seorang pria yang mencintai kebebasan, menyukai surfing, dan menulis blog, ia menetap di Bali setelah ayahnya melepasnya untuk menjadi seorang yang mandiri. Menceritakan kehadirannya di pemakaman seorang yang bahkan tak 
dikenal di Jakarta dengan alasan ia harus tahu apa sebenarnya hubungan dirinya dengan seseorang yang meninggal tersebut.

\section{b. Tokoh Roti}

Latar ini menceritakan percakapan Tansen dan pak Hadi tentang toko roti yang tidak beroperasi lagi dan mendeskripsikan keadaan tokoh roti tersebut dengan menggunakan majas personifikasi. Melalui latar ini pula dideskripsikan tokoh dan karakternya. Hal tersebut dapat dilihat dari kutipan berikut ini.

Tanpa basa-basi, ia langsung menarik sebuah kursi, mempersilahkanaku duduk, "Sebentar, saya bikinkan kopi."Sambil menunggu, aku melihat sekeliling. Toko itu ternyata bekas toko roti atau toko kue, masih berjajar etalase kaca yang memburam, foto-foto hitam putih yang menguning, beberapa pasang meja dan bangku antik. Bagian dalam tokoh ini jauh lebih terawat dibandingkan luarnya. Ubin bercorak ini tampak bersih, semua barang masih diletakkan secara rapi, termasuk mesin kasir yang kuduga umrnya lebih tua daripada republik Indonesia. (Madre,hal.6)

"Dari cerita pak Hadi, akhirnya aku tahu bahwa tempat itu memang toko roti yang mati suri.sudah lima tahun tak beroperasi. "Tan de Bakker" adalah nama aslinya.berdiri 1943. Tahun 60-an berubah nama menjadi Toko Roti Tan. Seiring bermunculannya bakery-bakery modern, Toko Roti Tan tenggelam pelan-pelan.(Madre,hal.7).

Keterangan di atas menjelaskan bagian dalam toko roti dan keberadaan toko roti tersebut ada sejak kapan. Dengan menggunakan majas personifikasi Toko Roti Tan tenggelam pelan-pelan, pengarang menggambarkan keadaan toko roti tersebut seiring perkembangan zaman.

\section{Latar Waktu}

Latar waktu dalam cerpen Madre karya Dewi Lestari berkaitan dengan kapan peristiwa dalam cerita terjadi. Baik peristiwa yang sedang terjadi maupun peristiwa yang telah berlalu. Selain itu, terjadi peputaran waktu baik itu darihari, bulan, dan tahun mengkuti jalanya cerita dalam cerpen. Secara kronologis, waktu peristiwa yang terjadi dalam cerita berlangsung selama dua minggu. Berikut ini latar waktu dalam Cerpen Madre karya Dewi Lestari. 


\section{a. Perputaran Hari: Pagi, Siang, dan Malam}

Awan hitam yang menggantung sejak dini hari akhirnya tumpah menjadi hujan lebat. Tepat saat aku tiba di pemakaman orang yang tak ku kenal.Siapa dia? Itu pertanyaanku pertama. Kenapa aku? Itu pertanyaanku berikutnya. Keduanya akan terjawab pagi ini. (Madre, hal.1)

Dari keterangan tokoh utama, diketahui bahwa pada saat itu ia berada di tempat pemakaman pada pagi hari. Sebenarnya kata dini hari menunjukkan pukul $03.00-05.00$ pagi, tetapi terdapat penekanan pada bagian akhir kalimat bahwa saat itu Tansen berada di tempat pemakaman pada pagi hari. Hal ini diperjelas lagi dengan kutipan berikut.

Sudah tidak ada siapa-siapa lagi di situ. Acara pemakaman selesai sejak setengah jam yang lalu. Sengaja aku datang terlambat agar tidak bertemu siapa-siapa. (Madre, hal.2)

Dengan disebutkan sudah selesai pemakaman setengah jam yang lalu sebelum Tansen tiba, maka waktu dini hari secara tidak langsung menunjukkan waktu keberadaan Tansen pada hari itu dan bukan menunjukkan waktu sebenarnya dari kata dini hari.

Di dalam cerpen penyebutan nama hari dalam siklus hidup waktu peristiwa secara kronologis hanya satu kali yaitu hari Senin.

Senin dini hari, saat semua bangunan di jalanan ini tertidur lelap dalam gelap, dapur kami terjaga. Terang benderang. Semarak seperti kenduri. (Madre, hal.36)

Dalam kutipan peristiwa tersebut, pengarang menjelaskan aktivitas yang sedang berlangsung di dapur toko roti Tan de Bakker pada hari Senin pagi. Selanjutnya, pengarang menyelesaikan cerita dengan menggunakan kata dini hari pula seperti saat pembukaan cerita. Kata dini hari pada kutipan tersebut juga mendeskripsikan pada saat itu. Tetapi bedanya pengarang menyebutkan bahwa dua minggu sejak Tansen berada di Jakarta tepatnya di toko roti Tan, tansen diberikan Celemek dan penutup kepala untuk di pakai sebagai tanda bahwa sejak hari itu Tansen sudah kembali membuka Toko Roti Tan de Bakker yang diwariskan padanya.

Dini hari. Tepat dua minggu sejak aku penutup terdampar di Jakarta. Pak Hadi melemparkan celemek untuk kupakai. Menyusul, kepala. (Madre, hal.44) 
Dari pagi terjadi perputaran waktu ke malam hari. Hal ini dapat dilihat bahwa pada Saat itu Tansen menceritakan kembali kejadian yang di alaminya pada suatu malam di lantai dua ruko kuno yang diwarisakan pak Tan pada pak Hadi sejak lima tahun lalu.

Malam itu aku tak bisa tidur. Tiket busku pulang ke Bali hangus sudah. Alihalih tertidur di jok bus, aku berbaring terjaga di segelar kasur tipis di lantai dua ruko kuno itu, yang ternyata adalah tempa tinggal pak Hadi selama ini. (Madre, hal. 9)

Kutipan diatas menceritakan kembali kejadian yang di alami Tansen pada malam hari selama dia berada di kota Jakarta.

Tansen yang awalnya ingin menjual Madre kepada Mei akhirnya membatalkan niatnya karena memikirkan nasib kelima pegawai terakhir toko roti Tan; pak Joko, bu Sum, bu Dedeh, bu Cory dan pak Hadi. Terutama pak Hadi yang dengan setia menjaga Madre sambil menanti kedatangan Tansen sebagai ahli waris sekaligus penerus bisnis roti milik keluarganya.

\section{b. Perputaran Tahun}

Dalam kurung waktu tersebut diceritakan keadaan toko roti milik pak Tan yang sudah lima tahun tak beroperasi. Tokoh Tansen menjelaskan awal berdirinya toko roti "Tan de Bakkery" tahun 1943 setelah itu tahun 60-an berubah nama menjadi Toko Roti Tan, sehingga jalan cerita merupakan alur sorot balik. Pengarang juga menggunakan majas hiperbola pada kutipan 'Toko Roti Tan tenggelam pelan-pelan' untuk menjelaskan keadaan toko roti tersebut yang bisnisnya makin menyusut seiring munculnya toko-toko roti modern. Kutipan ini memberikan makna bahwa tema yang digunakan untuk membangun jalan cerita adalah sebuah toko roti kuno. Dimana

diceritakan sebuah toko roti berusia 70 tahun, yang dibangun pada tahun 1943 dan masih bertahan di tengah daerah modern.

Dari cerita pak Hadi, akhirnya aku tahu bahwa tempat itu memang toko roti yang mati suri. Sudah lima tahun tak beroperasi. "Tan de Bakker" adalah nama aslinya, berdiri 1943. Tahun 60-an berubah nama menjadi Toko Roti Tan. Seiring bermunculannya bakerry-bakerry modern, Toko Roti Tan tenggelam pelan-pelan. (Madre, hal. 7) 
Kutipan di atas menjelaskan bahwa terjadi perputaran Tahun yang terjadi ketika pak Hadi menceritakan kembali kejadian yang di alami toko roti Tan de Bakker, 5 tahun lalu kepada Tansen.

\section{Latar Suasana}

Penggambaran keadaan setiap peristiwa yang terjadi dalam Cerpen Madre karya Dewi Lestari dengan menggunakan dua macam latar suasana yaitu, suasana lahir dan suasana batin. Secara implisit dan secara eksplisit, pengarang menampilkan suasana batin yang dialami oleh setiap tokoh dalam cerita serta suasana lahir pada keadaan atau lingkungan sekitar tokoh saat mengalami peristiwa tertentu.

\section{a. Suasana Sepi}

Di awal cerita, Tansen menjelaskan bahwa ia hadir di lokasi pemakaman pak Tan saat acara pemakaman sudah selesai sejak tengah jam yang lalu sehingga hanya ia seorang diri di lokasi pemakaman itu.

Sudah tidak ada siapa-siapa lagi di situ. Acara pemakaman selesai sejak setengah jam yang lalu. Sengaja aku datang terlambat agar tidak bertemu siapa-siapa. Misteri ini tak perlu bertambah ruwet dengan ekstra drama.

(Madre, hal.2)

Berdasarkan cerita tersebut, secara tidak langsung pengarang menggambarkan keadaan lokasi tempat tokoh berada saat itu. Hal ini diperkuat dengan penggunaan sudut pandang orang pertama aku yang menceritakan keberadaan dirinya saat di lokasi pemakaman. Dengan menjelaskan saat ia hadir setelah selesai pemakaman setangah jam yang lalu dan sudah tidak ada siapa-siapa di lokasi pemakaman tersebut maka peneliti menyimpulkan bahwa latar suasana yang tergambar secara tidak langsung dalam cerita tersebut adalah suasana sepi. 


\section{b. Suasana Mengharukan}

Pak Hadi yang merupakan karyawan Tan de Bakker bercerita tentang keadaan yang di alami toko roti mereka seiring perkembangan zaman.

"Tokoh sudah ndak ada untung. Cuma cukupan buat gaji pegawai tapi Tan bertahan terus.katanya Madre jangan dibikin nganggur."

"Madre?"

"Karyawan di sini Cuma lima orang.Bisnis nyusut terus.Lama-lama kami kerja ndak digaji. Akhirnya nyerah juga dia. Ndak tega sama kami. ”Pak Hadi tersenyum kecut." yang penting, Madre jangan mati. Itu saja yang kami jaga” (Madre, hal, 6)

Dalam dialog di atas, pak Hadi menceritakan peristiwa yang dialami dirinya dan karyawan yang lain selama bekerja di toko roti Tan. Pengarang menggunakan susdut pandangn campuran karena menempatkan dirinya bergantian dari satu tokoh ke tokoh lainnya dengan sudut pandang yang berbeda-beda "kami dan dia". Melalui kutipan tersebut dapat dikatakan bahwa tema yang diangkat dalam membangun cerita adala tema kemanusiaan. Karena secara garis besar dari isi kutipan ada sifat kepedulian yang dimiliki tokoh dalam cerita. Kutipan tersebut juga secara tidak langsung menjelaskan sifat pak Tan yang tekun, pekerja keras dan teguh pendirian. Sementara pak Hadi dan keempat karyawan yang lain digambarkan sebagai orang yang tidak patah semangat dan peduli. Peneliti menyimpulkan kutipan di atas sebagai gambaran latar suasana haru karena pengarang menekankan karakter tokoh dengan menggunakan majas personifikasi untuk mendeskripsiskan rasa peduli mereka sekalipun pada sebuah adonan roti.

\section{Latar Sosial Budaya}

Dalam cerpen Madre karya Dewi Lestari tergambar lingkungan sosial-budaya masyarakat di kota Jakarta pada umumnya sebelum dan saat masa modern. Lebih spesifik lagi, warna budaya yang ditampilkan dalam cerita ini adalah budaya Tionghoa dan India. Lewat cerita Madre pengarang memberikan pengetahuan mengenai dua kebudayaan yang sama kuat. Bahkan pengarang mencoba menyatukan kedua kebudayaan itu melalui pernikahan kakek dan nenek Tansen, Tan Sie Gie dan Lakshmi. Berikut ini gambaran latar sosial-budaya dalam cerita Madre. 


\section{a. IlmuPengetahuan}

Pengarang memilih latar belakang India ras nenek Tansen sebagai penjelas ilmu pengetahuan dalam cerpen tersebut. Roti yang berkembang di Indonesia itu pertama kali di bawa oleh orang India. Bangsa India lah yang memperkenalan roti pada bangsa Indonesia melalui perdangangan. Warisan yang berikan oleh Lakshmi, kini dilalukan juga oleh Tansen cucunya dalam menggunakan dan merawat Madre sebagaimana mestinya.

Setelah semua adonan roti beres, pak Hadi memanggilku, "Tansen, ayo, kamu yang kasih makan Madre," ia menyodorkan stoples kaca itu, "ini hari penting buat kalian berdua." (Madre, hal. 27)

Entah kapan aku akan terbiasa dengan cara mereka memperlakukan Madre dengan sangat manusiawi. Aku masih merasa lucu dikerubuti mereka yang saksama mengamatiku mengadukkan tepung dan air ke dalam Madre, seolah-olah adonan itu akan menggeliat kesenangan bagai kucing yang disayang-sayang majikan. Dan, setelah stoples-stoples berisi Madre disusun lagi dikulkas, sebelum menutup pintunya, Bu Cory sempat-sempatnya berkata, "Selamat istirahat, Madre.” (Madre, hal. 28)

Kutipan di atas menggambarkan bahwa sementara Tansen mendapatkan ilmu baru dari pak Hadi dan karyawan-karyawan lainnya yang selama ini belum pernah ia dapatkan yaitu memberi makan Madre dengan mengadukkan tepung dan air ke dalam Madre. Selain itu Tansen juga mendapatkan pelajaran baru dari pak Hadi yaitu ia harus, merawat dan menyanggi Madre seperti kucing yang disayang-sayang majikanya sama seperti yang selama ini mereka lakukan kepada Madre.

\section{b. Arsitektur}

Setiap bentuk bangunan pasti akan berubah seiring perkembangan zaman. Seperti halnya dalam kisah Madre. Dimulai dengan penggambaran toko roti tua sampai mal.

Tempat itu adalah bekas tokoh tua tanpa plang di daerah Jakarta tua. Ruko kuno dua lantai yang tak terurus; cat mengelupas, tembok kehitaman oleh lembap dan jamur, plafon menganga disana sini, kayu-kayu melunak oleh rayap dan air hujan. Aku tidak yakin tempat ini dihuni. Tak ada tanda-tanda kehidupan selain gerak gerik laba-laba yang bersarang di mana-mana. (Madre, hal. 5)

Sambil menunggu, aku melihat sekeliling. Toko itu ternyata bekas toko roti atau toko kue. Masih berjajar etalase kaca yang memburam, foto-foto hitam putih yang menguning, beberapa pasang meja dan bangku antik. Bagian 
Latar Cerpen Madre dalam Kumpulan Cerita Madre Karya Dewi Lestari (Analisis

Struktural)

dalam toko ini jauh lebih terawat dibandingkan luarnya. Ubin bercorak ini tampak bersih, semua barang masih diletakkan secara rapi, termasuk mesin kasir yang kuduga umurnya lebih tua daripada Republik Indonesia. (Madre, hal.6)

Kutipan di atas menggambarkan bahwa Toko roti yang di datangi Tansen ini adalah toko roti tua. Hal ini dapat di lihat dari bagian luar dan dalam bangunan yang arsitektur masih arsitektur bangunan zaman dulu, hal ini juga dapat dibuktikan dengan bagian dalam gedung yang masih terdapat barang-barang antik seperti, meja dan bangku dan juga mesin kasir yang diduga umurnya lebih tua daripada Republik Indonesia.

Kami pun berangkat ke Jakarta Selatan, menuju mal tempat Fairy Bread memiliki gerainya yang terbesar. (Madre, hal. 40)

tiba di Fairy Bread. Langkah pak Hadi terlihat melambat. Ekspresinya yang terpukau tak bisa disembunyikan. Matanya nyaris tak berkedip. Gerai Fairy Bread didominasi kaca. Lampu terang benderang menyoroti nampannampan kaca berisi roti yang terpajang di rak terbuka. Dapurnya yang transparan memperlihatkan para pegawai hilir mudik membuat roti dan kue.

(Madre, hal. 40)

Dalam kutipan di atas menjelaskan bahwa pak Hadi dan Tansen di ajak Mei pergi ke Jakarta Selatan, menuju mal tempat Fairy Bread memiliki gerainya yang terbesar Fairy Bread yang terletak di sebuah Mall yang begiu besar. Pak Hadi pun begitu terpukau melihat bangunan Fairy Bread yang semegah dan semewah itu yang belum pernah di lihatnya pada zamannya dulu. Hal ini menandakan bahwa setiap bangunan pastinya arsitekturnya akan berubah seiring perkembangan zaman, hal ini dapat dilihat pada Toko Roti Tua dan bangunan Fairi Bread yang, dibangun pada zaman yang berbeda dimana bentuk bangunan dan arsitekturnya berbeda sesuai dengan zamannya masing-masing bangunan tersebut di bangun.

\section{KESIMPULAN}

Berdasarkan hasil analisis dapat disimpulkan bahwa latar-latar yang ada dalam karya prosa Indonesia, termasuk dalam Cerpen Madre suatu perubahan zaman maupun juga konteks sosial budaya yang melatari cerita tersebut dibuat. Latar tempat dalam cerpen Madre adalah Tempat Pemakaman Umum Etnis Tionghoa, toko roti Tan de Bakker. Selain latar tempat terdapat latar waktu dalam cerpen Madre yang menggambarkan, perputaran hari : Pagi, Siang, dan malam. Perputaran Tahun, masa kecil Tokoh utama. Kemudian, latar suasana meliputi suasana sepi, suasana mengharukan. Latar sosial budaya menggambarkan sosial budaya yang didominasi oleh etnis tionghoa. 
Dari keempat jenis latar tersebut yang paling dominan pada cerpen ini adalah latar tempat dikarenakan dari awal cerita sampai akhir cerita hampir semua jalan ceritanya terjadi di dalam Toko roti Tan de bakker di kota Jakarta. Dapat dimaknai bahwa latar tempat tersebut merupakan Toko roti Tan de Bakker juga dijadikan sebagai tempat tinggal sehingga 80\%-90\% kehidupan tokoh dijalani di tempat usaha tersebut. Hal ini menggambarkan secara tersirat kehidupan sosial budaya etnis Tionghoa yang sangat ulet dan tekun dalam menjalankan bisnis keluarga. Dengan demikian dapat disimpulkan juga bahwa latar merupakan salah satu unsur yang signifikan dalam memahami isi sebuah cerita atau karya prosa.

Dengan demikian, dapat disimpulkan juga bahwa latar merupakan salah satu unsur yang signifikan dalam memahami isi sebuah cerita atau karya prosa. Latar-latar yang ada dalam karya prosa Indonesia dapat menggambarkan suatu perubahan zaman maupun juga konteks sosial budaya yang melatari cerita itu di buat.

\section{DAFTAR PUSTAKA}

Endraswara, Suwardi. 2003. Epistimologi, Model, Teori, dan Aplikasi Yogyakarta: Media Pressindo.

Lestari, Dewi. 2013: Madre Kumpulan Cerita Pendek. Yogyakarta: Bentang. Moleong J. Lexy. 2017. Metodologi Penelitian Kualitatif. Bandung: Remaja Rosdakarya.

Nurgiyantoro, Burham. 2015. Teori pengkajian Fiksi. Yogyakarta: Gadjah Mada University Press. 
Latar Cerpen Madre dalam Kumpulan Cerita Madre Karya Dewi Lestari (Analisis Struktural) 